University of Nebraska - Lincoln

DigitalCommons@University of Nebraska - Lincoln

\title{
Conservation Biology for Suites of Species: Demographic Modeling for Pacific Island Kingfishers
}

Dylan C. Kesler

Oregon State University, DylanKesler@picra.net

Susan M. Haig

U.S. Geological Survey, Susan_Haig@usgs.gov

Follow this and additional works at: https://digitalcommons.unl.edu/usgsstaffpub

Kesler, Dylan C. and Haig, Susan M., "Conservation Biology for Suites of Species: Demographic Modeling for Pacific Island Kingfishers" (2007). USGS Staff -- Published Research. 669.

https://digitalcommons.unl.edu/usgsstaffpub/669

This Article is brought to you for free and open access by the US Geological Survey at DigitalCommons@University of Nebraska - Lincoln. It has been accepted for inclusion in USGS Staff -- Published Research by an authorized administrator of DigitalCommons@University of Nebraska - Lincoln. 


\title{
Conservation biology for suites of species: Demographic modeling for Pacific island kingfishers
}

\author{
Dylan C. Kesler ${ }^{a, b, *}$, Susan M. Haig ${ }^{a, 1}$ \\ aUSGS Forest and Rangeland Ecosystem Science Center, 3200 SW Jefferson Way, Corvallis, OR 97331, USA \\ ${ }^{\mathrm{b}}$ Department of Fisheries and Wildlife, Oregon State University, Corvallis, OR 97331, USA
}

\section{A R T I C L E I N F O}

Article history:

Received 7 June 2006

Received in revised form

22 December 2006

Accepted 26 December 2006

Available online 20 February 2007

Keywords:

Demographic model

Island avifauna

Micronesian kingfisher

Pacific island conservation

Population model

Population suite

Todiramphus cinnamominus

reichenbachii

Halcyon cinnamomina

\begin{abstract}
A B S T R A C T
Conservation practitioners frequently extrapolate data from single-species investigations when managing critically endangered populations. However, few researchers initiate work with the intent of making findings useful to conservation efforts for other species. We presented and explored the concept of conducting conservation-oriented research for suites of geographically separated populations with similar natural histories, resource needs, and extinction threats. An example was provided in the form of an investigation into the population demography of endangered Micronesian kingfishers (Todiramphus cinnamominus). We provided the first demographic parameter estimates for any of the 12 endangered Pacific Todiramphus species, and used results to develop a population projection matrix model for management throughout the insular Pacific. Further, we used the model for elasticity and simulation analyses with demographic values that randomly varied across ranges that might characterize congener populations. Results from elasticity and simulation analyses indicated that changes in breeding adult survival exerted the greatest magnitude of influence on population dynamics. However, changes in nestling survival were more consistently correlated with population dynamics as demographic rates were randomly altered. We concluded that conservation practitioners working with endangered Pacific kingfishers should primarily focus efforts on factors affecting nestling and breeder survival, and secondarily address fledgling juveniles and helpers. Further, we described how the generalized base model might be changed to focus on individual populations and discussed the potential application of multi-species models to other conservation situations.
\end{abstract}

(c) 2007 Elsevier Ltd. All rights reserved.

\section{Introduction}

Conservation biologists have long embraced the use of information from surrogate populations for managing endangered species (Bednarz, 1987; Sydeman, 1989; Legge, 2000; Linacre et al., 2004; Bar-David et al., 2005; Doak et al., 2005). Surrogates can be necessitated by a lack of knowledge about the particular population of interest, combined with time and resource constraints that prevent thorough investigations. Some endangered species have also been so affected that population remnants may not reflect historic behavior as accurately as surrogates. However, few researchers have initiated investigations or presented results with the intent of providing conservation-oriented information useful to the management of similar populations. We emphasize the need for conducting research and structuring results to benefit geographically

\footnotetext{
* Corresponding author: Present address: Biological Sciences, 4095 Derring Hall (0406), Virginia Polytechnic Institute and State University, Blacksburg, VA 24061, USA. Tel.: +1 5402313905.

E-mail addresses: DylanKesler@picra.net (D.C. Kesler), Susan-Haig@usgs.gov (S.M. Haig).

1 Tel.: +1 5417507482 .
}

0006-3207/\$ - see front matter @ 2007 Elsevier Ltd. All rights reserved.

doi:10.1016/j.biocon.2006.12.023 
separated populations of related organisms that share similar natural histories, resource needs, and extinction threats.

In many regions there are suites of geographically disparate populations that are phylogenetically related and ecologically similar, but the pattern is especially prevalent among the avifauna of oceanic islands. For example, island groups in Pacific Oceania host resident populations of doves (Ptilinopus spp., Gallicolumba spp.), fantails (Rhipidura spp.), whiteeyes (Zosterops spp.), reed-warblers (Acrocephalus spp.), and honeyeaters (Myzomela spp.). Similarly, larger islands are characterized by kingfishers (Todirhamphus spp.), flightless rails (Gallirallus spp.; Porzana spp.), megapodes (Megapodius spp.), and pigeon species (Ducula spp.; Baker, 1951; Pratt et al., 1987; Mayr and Diamond, 2001). These small pockets of endemism are also subject to extreme extinction rates, as over $90 \%$ of the world's recent bird extinctions have occurred on islands (Johnson and Stattersfield, 1990). Within the aforementioned 11 genera, 76 species in Oceania are listed as vulnerable, threatened, or in danger of extinction (US Fish and Wildlife Service, 1984; International Union for Conservation and Natural Resources, 2004). Despite these dire threats, however, researchers have failed to describe even the most basic natural history characteristics for these species.

One option for addressing the immediate need for information is to use surrogate populations and plan research so that results are useful to conservation efforts for suites of ecologically similar and related taxa. Population biology is an especially appealing arena for generalized research because population models are some of the most fundamental tools used by those managing endangered species (Casswell, 2000; Morris and Doak, 2002; Beissinger et al., 2006), yet many modeling attempts have been hindered by a lack of life history data (Ruggiero et al., 1994; Caughley and Gunn, 1996; Beissinger and McCullough, 2002). We present an example of a demographic investigation of the Pohnpei Micronesian kingfisher (Todiramphus cinnamominus reichenbachii) that was initiated with the intent of benefiting both the Pohnpei population of kingfishers and related endangered Pacific island congeners.

\section{Pacific kingfishers}

Twelve Pacific region Todiramphus kingfisher species are listed as vulnerable, threatened, or endangered by federal and international conservation authorities (US Fish and Wildlife Service, 1984; International Union for Conservation and Natural Resources, 2004). Life histories of the birds are generally similar across the islands, as they are terrestrial forest birds inhabiting similar vegetation communities and climates (Mueller-Dombois and Fosberg, 1998). The kingfishers are also nutritional generalists that nest in cavities excavated from the soft wood of decaying trees or the soft material of arboreal termite nests (Marshall, 1989; Fry and Fry, 1992; Kesler and Haig, 2004, 2005a). Nonetheless, there are critically few data available for conservation practitioners to use in managing these endangered birds.

Demographic data are of particular interest to those involved with conservation efforts for the Micronesian kingfisher (US Fish and Wildlife Service, 2004), Marquesas
Kingfisher (T. godeffroyi), Niau Kingfisher (T. gambieri), and the Pacific Kingfisher (T. tuta; A. Gouni, Société d'Ornithologie de Polynésie, personal communication). Of these, the Guam subspecies of Micronesian kingfisher (T. c. cinnamominus) is in perhaps the most perilous predicament, as they are extinct in the wild and only exist in a captive population (Marshall, 1989; Haig and Ballou, 1995; Haig et al., 1995). Plans are now underway to reintroduce the Guam Micronesian kingfisher back to native habitats and demographic data are vital to the effort (US Fish and Wildlife Service, 2004). Similarly, conservation practitioners responsible for T. c. reichenbachii, T. c. pelewensis, T. godeffroyi, T. gambieri, and T. tuta are faced with the likely possibility that needed demographic information cannot be obtained from each respective population in time to prevent extinction. Herein, we explored the use of foundational demographic data from Pohnpei Micronesian kingfishers (T. c. reichenbachii) in the development of a generalized Todiramphus kingfisher population model. We then used the model to evaluate the potential importance of demographic parameters to population dynamics in a range of Pacific Todiramphus kingfisher species.

\section{Methods}

\subsection{Study area}

Research was conducted on the island of Pohnpei, Federated States of Micronesia $\left(6^{\circ} 52^{\prime} \mathrm{N}, 158^{\circ} 13^{\prime} \mathrm{E}\right)$. Pohnpei is a circular island with an approximate diameter of $20 \mathrm{~km}$ circumscribing the highest peak in the Micronesian chain (nearly 800 m, Engbring et al., 1990). Three sites were selected for this investigation including the Ranch $\left(6^{\circ} 57^{\prime} \mathrm{N}, 158^{\circ} 12^{\prime} \mathrm{E}\right)$, College of Micronesia (COM; $\left.6^{\circ} 54^{\prime} \mathrm{N}, 158^{\circ} 9^{\prime} \mathrm{E}\right)$, and Palikir $\left(6^{\circ} 55^{\prime} \mathrm{N}\right.$, $\left.158^{\circ} 9^{\prime} \mathrm{E}\right)$ study areas. The study sites have been described extensively elsewhere (Buden, 2000; Kesler, 2002, 2006; Kesler and Haig, 2004, 2005a,b, 2007a,b).

\subsection{Study population and field methods}

Pohnpei Micronesian kingfishers breed as pairs and cooperative groups (Kesler, 2002; Kesler and Haig, 2005a,b). For the purposes of this study, we followed the terminology of recent literature by using "dominant" to refer to the putative breeders on a territory and "helper" for offspring that delayed dispersal through subsequent reproductive attempts. Additionally, we used hatch-year (HY) to describe progeny of the most recent breeding season, and after-hatch-year (AHY) to describe all non-juveniles.

We radio-marked and color-banded a population of Micronesian kingfishers on Pohnpei study areas between 1999 and 2004. The study population was intensively observed from January to July 1999, March to August 2000, September 2001, September 2002 to January 2003, and October and November 2004. Micronesian kingfishers were captured in mist nets and the age and sex of each individual was determined using genetic analyses, plumage, and morphological characteristics (Kesler et al., 2006). We captured 39 juveniles (16 male [M], 23 female $[\mathrm{F}]), 14$ helpers $(10 \mathrm{M}, 4 \mathrm{~F})$, and 44 dominants $(23 \mathrm{M}, 21 \mathrm{~F})$, and fitted each individual with a unique combination of 
colored leg-bands and a numbered aluminum US Fish and Wildlife Service band. In 1999, 2000, and 2002, we fitted $1.8 \mathrm{~g}$ telemetry packages (Holohil Systems Ltd., Ottawa, Canada) to Micronesian kingfishers using leg-harnesses (Rappole and Tipton, 1991). We radio-marked 16 juveniles (7M, 9F), which were subsequently observed for 130 bird*weeks during the first 10 months post-fledge (839 telemetry locations, 579 bird*days). Additionally, we radio-marked 13 helpers $(8 \mathrm{M}, 5 \mathrm{~F})$ and 35 dominants $(19 \mathrm{M}, 16 \mathrm{~F})$, which were monitored for 128 helper bird*weeks and 443 dominant bird*weeks. Radiomarked individuals were located using triangulation (Kesler and Haig, 2007a,b), and birds were approached on foot to verify mortality if movement was not detected during three consecutive days.

\subsection{Population model}

We outlined a conceptual Todiramphus kingfisher population model (Fig. 1) to guide the development of a quantitative projection matrix. Briefly, the conceptual model describes a cooperatively breeding population that includes helpers who delay dispersal and independent attempts at reproduction. To translate the conceptual model into a quantitative deterministic population projection matrix we used data from six years of color-band resighting, three years of radio telemetry, and numerous nesting and behavior observations.

\subsubsection{Survival}

Survival was assessed in two stages. First, we used odds ratio tests and Cormack-Jolly-Seber modeling of color band resight data to determine population model structure. Potential differences in juvenile survival (fledging to first year) on cooperatively breeding ( $n=12$ fledglings) and pair-breeding $(n=19$ fledglings) territories were assessed by comparing the odds of resighting marked fledglings during subsequent years. To determine whether survival in juveniles, helpers, and dominants should be separated by class, sex, both, or neither in the matrix model, Cormack-Jolly-Seber estimation methods were applied to color band resight data (described above; Pollock et al., 1990; Lebreton et al., 1992). We estimated both apparent survival and the probability of resight because individuals may have been present on study areas but missed when resighting color-bands (Anders and Marshall, 2005). We constructed biologically reasonable survival models with
Table 1 - Models of annual survival $(\phi)$ and recapture probabilities ( $p$ ) for color-banded Pohnpei Micronesian Kingfishers between 1999 and 2004

\begin{tabular}{|c|c|c|c|c|}
\hline Model & K & $\mathrm{AIC}_{\mathrm{C}}$ & $\Delta_{\mathrm{i}}$ & $w_{i}$ \\
\hline$\phi_{\mathrm{j}, \mathrm{AHY} ; \mathrm{P} \bullet}$ & 3 & 187.642 & 0.00 & 0.37 \\
\hline$\phi_{\mathrm{j}, \mathrm{h}, \mathrm{d} ; \mathrm{p} \bullet}$ & 4 & 189.195 & 1.57 & 0.17 \\
\hline$\phi_{j, \mathrm{AHY} * \mathrm{sex}} ; p \bullet$ & 4 & 189.687 & 2.06 & 0.13 \\
\hline 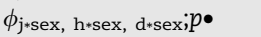 & 7 & 190.039 & 2.42 & 0.11 \\
\hline$\phi_{\mathrm{j}, \mathrm{h}, \mathrm{d} * \mathrm{sex}} ; p \bullet$ & 5 & 190.664 & 3.04 & 0.08 \\
\hline$\phi_{\mathrm{j}, \mathrm{AHY}} ; p_{\mathrm{j}, \mathrm{h}, \mathrm{d}}$ & 5 & 191.204 & 3.56 & 0.06 \\
\hline$\phi_{\mathrm{j}, \mathrm{h}, \mathrm{d}} p_{\mathrm{j}, \mathrm{h}, \mathrm{d}}$ & 6 & 192.943 & 5.32 & 0.02 \\
\hline$\phi_{\mathrm{juv}, \mathrm{AHY}+\mathrm{sex}} ; p_{\mathrm{j}, \mathrm{h}, \mathrm{d}}$ & 6 & 193.339 & 5.71 & 0.02 \\
\hline$\phi_{\mathrm{j} * \mathrm{sex}, \mathrm{h} * \operatorname{sex}, \mathrm{d} * \mathrm{sex}} ; p_{\mathrm{j}, \mathrm{h}, \mathrm{d}}$ & 9 & 193.873 & 6.25 & 0.01 \\
\hline$\phi_{\mathrm{j}, \mathrm{h}, \mathrm{d} * \mathrm{sex}} ; p_{\mathrm{j}, \mathrm{h}, \mathrm{d}}$ & 7 & 194.462 & 6.84 & $<0.01$ \\
\hline$\phi \bullet ; p \bullet$ & 2 & 196.892 & 9.27 & $<0.01$ \\
\hline$\phi \bullet ; p_{\mathrm{j}, \mathrm{h}, \mathrm{d}}$ & 4 & 199.176 & 11.55 & $<0.01$ \\
\hline
\end{tabular}

Also noted for each model is the number of parameters $(K)$, second-order Akaike's Information Criterion $\left(\mathrm{AIC}_{\mathrm{c}}\right.$ ) values, $\mathrm{AIC}_{\mathrm{c}}$ differences $\left(\Delta_{\mathrm{i}}\right)$, and $\mathrm{AIC}_{\mathrm{c}}$ weights $\left(w_{\mathrm{i}}\right)$. Subscript indicates model parameterization for juveniles (j), helpers (h), dominants (d), combined estimates for helpers and dominants (AHY), and all classes combined $(\bullet)$. Separate survival estimates were made for males and females when subscripts were modified by "sex. For example, $\phi_{\mathrm{j}, \mathrm{AHY} \text { *sex }}$ represents separate survival estimates for juveniles, a combined estimate for male helpers and male dominants, and a combined estimate for female helpers and female dominants.

covariates for sex and life-stage, and combined parameter estimates (Table 1). Models were ranked using Akaike's Information Criteria ( AIC $_{c}$; see Burnham and Anderson, 2002) in the live recapture module of Program Mark (White, 2005) and the top-ranked model was used to determine whether survival differed among social classes and sexes.

Second, radio-telemetry data were grouped in accordance with results from Cormack-Jolly-Seber modeling, and known-fate models (White, 2005; Kaplan and Meier, 1958) were used to estimate survival for simulation matrices. We used known-fate analyses rather than color-band resight results because they are less likely to be biased by birds that were present on study areas, but that went unseen. In accordance with odds ratio tests and model ranking analyses, we made a survival estimate for the period between fledging through the end of the first year ( $\left.\phi_{\text {juvenile}}\right)$, and a combined

\section{Cooperatively Breeding Population}

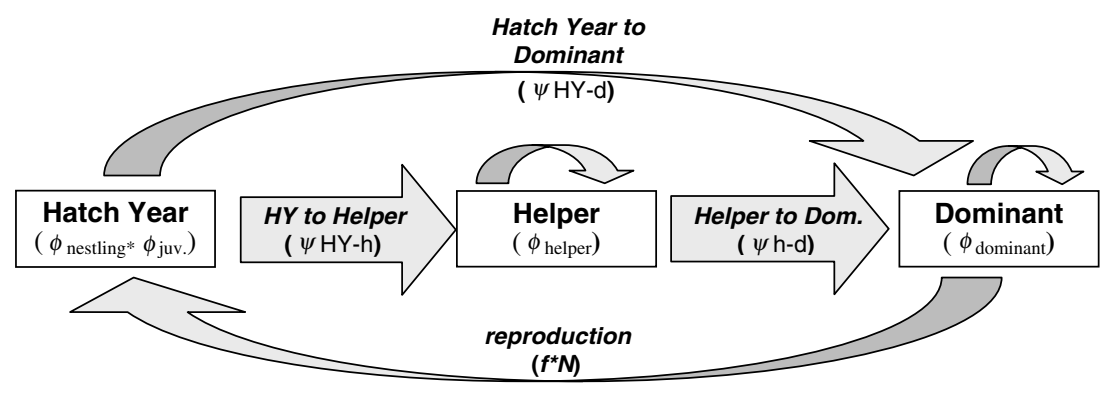

Fig. 1 - Conceptual population model for Pacific Todiramphus kingfishers, and associated model parameters. Parameters include survival $(\phi)$ and transition $(\psi)$ variables. 
estimate of after-hatch-year survival for helpers and dominants of both sexes ( $\left.\phi_{\mathrm{AHY}}\right)$. To estimate survival for an individual from the time that it was an egg through the first year of life, we combined juvenile survival estimates from the known fate analyses with previously published nestling survival estimates for Micronesian kingfishers ( $\phi_{\text {nestling }}=0.534$, Kesler, 2006). Previously published nestling survival was based on a study of both cooperative and pair-breeding nests, which were proportionally represented. Thus, survival for the first year of life, or hatch-year survival $\left(\phi_{\mathrm{HY}}\right)$ from both nestling and juvenile stages was:

$\phi_{\mathrm{HY}}=\phi_{\text {nestling }} * \phi_{\text {juvenile }}$.

\subsection{Reproduction}

Survival estimates (described above) included the period between laying and fledging, so parameters associated with reproduction were limited to the number of nest attempts by those that bred $(f)$, the number of eggs laid during each attempt, the potential for age structuring in reproductive success, and the proportion of the population that attempted to breed $(N)$. We used direct observations of 10 territories to determine the mean number of breeding attempts made by Micronesian kingfishers during 2000 fieldwork, when observers were present on study areas throughout the breeding season. Breeding attempts were directly observed as nests with eggs. Previously published findings indicated that Micronesian kingfishers were characterized by two-egg clutches (Kesler, 2002, 2006), and we assumed a 1:1 sex ratio for eggs.

To determine whether reproduction was age-structured and whether all pairs attempted to breed, we compared the odds of nesting in newly settled dominants ( $n=15$ male* years; 18 female*years) with dominants observed on territories during the previous years ( $n=15$ male*years; 14 female*years). We further compared the number of young at the end of each field season on newly settled territories with those on previously settled territories ( $n=30$ male and 32 female*years) to evaluate breeder experience.

\subsection{Social class transition}

We estimated the proportion of individuals transitioning among life history stages $(\psi)$ using resight observations of the 39 color-banded juvenile and 13 helper Micronesian kingfishers. Transitions were directly observed when in subsequent years juveniles became helpers or dominants, and when helpers became dominants (respectively, $\psi_{j-h}, 1-\psi_{j-h}, \psi_{h-d}$ ).

\subsection{Population model structure}

Following assessment of Pohnpei Micronesian kingfisher demographic parameters, a deterministic prospective population projection matrix model was structured to reflect a cooperatively breeding population of Todiramphus kingfishers. The model included a pulse-breeding population with a time step occurring immediately after laying, and with demographic parameters that were consistent across time. Both sexes have been observed as helpers and territory holders (Kesler and Haig, 2007a,b), so the model was based on females.

\subsection{Sensitivity, elasticity, and simulation analyses}

The prospective population projection matrix was employed in sensitivity and elasticity analyses, and in a simulation analysis to identify demographic parameters key to population dynamics and conservation (Caswell, 2001; Wisdom et al., 2000; Williams et al., 2001; Morris and Doak, 2002). We estimated the dominant eigenvalue $(\lambda)$, which represents the asymptotic rate of population change and provides a general measure of whether a population was projected to increase or decrease in size. Sensitivity $(S)$ and elasticity $(E)$ statistics were estimated by altering each parameter by 0.01 and using a "brute force" method to assess change in $\lambda$ (Heppell et al., 2000; Morris and Doak, 2002, p. 330). Sensitivity for each demographic parameter represents the amount of change in $\lambda$ associated with small changes in $\theta$, where $\theta$ was the demographic parameter of interest, or

$\mathrm{S}_{\theta}=\partial \lambda / \partial \theta$

(Williams et al., 2001, p. 151). Elasticity is a metric scaled to reflect the proportional change in $\lambda$ that was brought about by a similarly proportioned change in $\theta$, which facilitates comparisons among $\theta$ (Williams et al., 2001, p. 152):

$E_{\theta}=\frac{\partial \lambda / \partial \theta}{\lambda / \theta}$

To provide insight into how demographic parameters influenced model behavior across populations of Todiramphus kingfishers that were characterized by demographic rates different from those on Pohnpei, we simulated 10,000 combinations of randomly varied parameters. As a guideline for survival variation we used an interval that was equal in width to the $95 \%$ confidence intervals from the Cormack-Jolly-Seber estimates (Morris and Doak, 2002, p. 348), which were centered on mean survival estimates derived from the known fate analyses. The proportion of helpers transitioning to dominants varied between 0.25 and 0.75 , and juvenile to helper transition rates varied between 0 and 0.5 to represent a pair-breeding population of kingfishers and a population with a higher proportion of helpers than we observed in Pohnpei. Nestling survival ranged from 0.24 to 0.74 , which were previously published estimates for nestlings on pairbreeding and cooperatively breeding territories (Kesler, 2006). Annual nest attempts were varied from 1.4 to 2.0 , and the proportion of the population that bred ranged from 0.75 to 1.00 . Rates varied independently and they were randomly selected from a uniform distribution (Wisdom and Mills, 1997) generated by SAS (SAS Institute, 1999). We then recalculated $\lambda, S$, and $E$ for each simulated set of values. Microsoft Excel (Microsoft Corporation, Seattle) and Matrix and Linear Algebra adding for Excel (Fox's Team, 2005) were used to simulate value combinations, calculate and rank sensitivity and elasticity values for each, and summarize results.

As a second method of evaluating the influence of demographic parameters on $\lambda$ across combinations of demographic rates likely to characterize multiple Todiramphus kingfisher species, we used SAS (PROC REG). For simulated values, $\lambda$ was regressed against each parameter using linear regression. The resulting regression slopes $(m)$ reflected the predicted magnitude of each parameter's influence on $\lambda$ and the coefficient of determination $\left(r^{2}\right)$ values indicated the amount of 
variation in $\lambda$ accounted for by each parameter (Wisdom and Mills, 1997). Thus, $m$ represented the magnitude of each parameter's influence on $\lambda$, while $r^{2}$ provided insight into the stability of a parameter's effect within the range of demographic values likely to characterize multiple Pacific Todiramphus kingfishers. Unless otherwise noted, estimates were reported as means with 95\% confidence intervals (95\% CI) in parentheses and differences were considered statistically significant at $\alpha<0.05$.

\section{Results}

\subsection{Demographic parameter estimation}

\subsubsection{Survival}

We used color-band resight data, odds ratio tests, and Cormack-Jolly-Seber methods to determine the population projection matrix model structure. Odds ratio tests indicated that separate parameters were not warranted for juvenile survival on cooperative and pair-breeding territories because there was no difference in the odds of resighting individuals fledged from cooperative (three resighted) and pair-breeding territories during subsequent years (two resighted; $P>0.05$; $\log$ odds ratio $=0.87 ; 95 \%$ CI 2.80 to -1.06 ). The top-ranked model in the Cormack-Jolly-Seber analysis of color band resight data indicated that the population projection matrix should include separate survival estimates for juveniles and after-hatch-year individuals, but that further structuring was not necessary (Table 1). Thus, radio telemetry data for dominant and helper birds were pooled in accordance with results from the model ranking procedure, and known-fate analyses indicated an estimated $\hat{\phi}_{\mathrm{AHY}}$ of 0.577 $(95 \% \mathrm{CI}=0.326-0.794)$. Known-fate analysis of juvenile radio telemetry data yielded an estimated weekly survival rate of 0.977 (95\% CI 0.931-0.993) and $\hat{\phi}_{\text {juvenile }}$ estimate of 0.366 (95\% CI 0.088-0.777). When estimated juvenile survival was combined with previously published survival rates from laying to hatch (0.534; Kesler, 2006), the estimated probability that an individual survives from the time of laying through the next breeding season was $0.195\left(\hat{\phi}_{\mathrm{HY}}=0.534 * 0.366\right)$.

\subsubsection{Reproduction}

Nest observations and plumage characteristics suggested that breeding pairs initiated multiple nests each year. Renesting occurred on $70 \%$ of territories in 2000 , so we used 1.7 nesting attempts per year $(N)$ in the matrix model. When territories with newly settled dominants were compared to territories with dominants that had previously been observed, results showed no differences in either the odds of nesting $(P>0.05$; $\log$ odds ratio $=0.38,0.87 \mathrm{SE}$ for males; $0.18,0.99 \mathrm{SE}$ for females) or in the number of offspring on territories at the end of each breeding season (t-tests; for males $P=0.452$, mean offspring $=1.20$ on newly settled territories and 1.53 on previously settled territories; for females $P=0.948$, mean offspring $=1.33$ on newly settled territories and 1.36 on previously settled territories). Thus, results did not indicate strong age structuring in Micronesian kingfisher reproduction and suggested that an age-structured matrix model was not necessary. Failure to breed was primarily linked to anthropogenic activities (e.g. deforestation and fires), so we assumed that all birds attempted to breed for the point estimate model and that attempts ranged from 0.75 to 1 for simulation models.

\subsubsection{Social classes transition}

Observations of transitions among social classes were rare. One female marked as a juvenile was subsequently observed as a helper and four females were later observed as breeders. Additionally, four helpers $(3 \mathrm{M}, 1 \mathrm{~F})$ remained as such during subsequent observations and five $(2 \mathrm{M}, 3 \mathrm{~F})$ transitioned to dominant status. Estimated transition rates were therefore $0.2,0.8$, and 0.6 for $\hat{\psi}_{j-h}, 1-\hat{\psi}_{j-h}$, and $\hat{\psi}_{h-d}$, respectively.

\subsubsection{Model structure}

Using information from the survival, reproduction, and transition analyses, we developed the following cooperative breeding population projection matrix model:

$$
\begin{aligned}
A & =\left[\begin{array}{lll}
a_{11} a_{12} & a_{13} & \\
a_{21} & a_{22} & a_{23} \\
a_{31} & a_{32} & a_{33}
\end{array}\right] \\
& =\left[\begin{array}{lll}
\left(\hat{\phi}_{\mathrm{HY}} * f * N *\left[1-\hat{\psi}_{j-h}\right]\right) & \left(\hat{\phi}_{\mathrm{AHY}} * \psi_{h-d} * f * B\right) & \left(\hat{\phi}_{\mathrm{AHY}} * f * B\right) \\
\left(\hat{\phi}_{\mathrm{HY}} * \hat{\psi}_{j-h}\right) & \left(\hat{\phi}_{\mathrm{AHY}} *\left[1-\hat{\psi}_{h-d}\right]\right) & 0 \\
\left(\hat{\phi}_{\mathrm{HY}} *\left[1-\hat{\psi}_{j-h}\right]\right) & \left(\hat{\phi}_{\mathrm{AHY}} * \hat{\psi}_{h-d}\right) & \left(\hat{\phi}_{\mathrm{AHY}}\right)
\end{array}\right] \\
& =\left[\begin{array}{lll}
0.2658 & 0.549 & 0.9809 \\
0.0391 & 0.2564 & 0 \\
0.1564 & 0.3206 & 0.5770
\end{array}\right]
\end{aligned}
$$

The matrix element $a_{i j}$ represents the number of individuals in class $i$ at the next time step that will arise from those currently in class $j$ (Caswell, 2001; Morris and Doak, 2002). From left to right, columns represent hatch year, helper, and dominant classes. Elements in the top row were functions of survival and fecundity whereas those below were elements of survival and transition. The second matrix illustrates how elements were calculated from demographic parameter data presented above, and the third includes base-value point estimates. The $\lambda$ value for the cooperative breeding population projection matrix was 0.877 , which represents a declining population.

\subsubsection{Sensitivity, elasticity, and simulation analyses}

We evaluated the influence of demographic parameters on population dynamics using sensitivity and elasticity analyses (Table 2). Results from the point-estimate model indicated that survival of dominant breeders had the strongest influence on population dynamics $(E=0.623)$. Changes in the number of nests attempted per year, nestling and juvenile survival, and the proportion of the population breeding also substantially influenced $\lambda$. Changes in helper-associated parameters had relatively little influence on $\lambda$, which was likely a result of their minor contribution to reproduction within the model. The model also included transition parameters for the proportion of birds moving between social classes, but transitions did not remove individuals from the population entirely, so it follows that their elasticities were lower than other demographic parameters.

Simulations were used to gain insight into the population dynamics of Todiramphus kingfisher populations with demographic parameters different from those identified on the 
Table 2 - Elasticity $(E)$ and sensitivity $(S)$ results from the point-estimate model, and $r^{2}$ values for demographic parameter regressions with $\lambda$ in the simulation of randomly varied demographic parameters for Todiramphus kingfishers

\begin{tabular}{|c|c|c|c|c|c|}
\hline \multirow[t]{2}{*}{ Parameter } & \multicolumn{2}{|c|}{ Point estimate } & \multicolumn{3}{|c|}{ Simulation } \\
\hline & Base value & $S / E$ & Range & $90 \% \mathrm{E}$ interval $^{\mathrm{C}}$ & $r^{2 d}$ \\
\hline \multicolumn{6}{|l|}{ Reproduction } \\
\hline Nests $(N)$ & 1.7 & $0.191 / 0.325$ & $1.4-2.0$ & $0.184-0.359$ & 0.05 \\
\hline Breeding adults ( $f$ ) & 1 & $0.321 / 0.321$ & $0.75-1.00$ & $0.184-0.359$ & 0.03 \\
\hline \multicolumn{6}{|l|}{ Survival $(\phi)^{\mathrm{a}}$} \\
\hline$\phi_{\text {nestling }}$ & 0.534 & $0.607 / 0.325$ & $0.240-0.740$ & $0.184-0.359$ & 0.40 \\
\hline$\phi_{\text {juvenile }}$ & 0.366 & $0.887 / 0.325$ & $0.232-0.500$ & $0.184-0.359$ & 0.21 \\
\hline$\phi_{\text {helper }}$ & 0.577 & $0.091 / 0.052$ & $0.479-0.675$ & $0.019-0.120$ & $<0.01$ \\
\hline$\phi_{\text {dominant }}$ & 0.577 & $1.080 / 0.623$ & $0.479-0.675$ & $0.573-0.762$ & 0.26 \\
\hline \multicolumn{6}{|l|}{ Transitions $(\psi)^{\mathrm{b}}$} \\
\hline$\psi_{\text {hatch-year to helper }}$ & $1 / 5=0.2$ & $-0.174 /-0.035$ & $0.000-0.500$ & -0.070 to -0.009 & 0.02 \\
\hline$\psi_{\text {helper to dominant }}$ & $5 / 9=0.6$ & $0.032 / 0.018$ & $0.250-0.750$ & $-0.005-0.033$ & $<0.01$ \\
\hline $\begin{array}{l}\text { a Base value estim } \\
\text { model from color- } \\
\text { b Base values for } \psi \\
\text { study areas. } \\
\text { c The } 90 \% \text { E interv } \\
\text { d The } r^{2} \text { value rep }\end{array}$ & $\begin{array}{l}\text { sulted in know } \\
\text { analyses. } \\
\text { ed from observ } \\
\text { s the observed } \\
\text { mount of vari }\end{array}$ & $\begin{array}{l}\text { alyses of radio te } \\
\text { olor-banded Por } \\
\text { accounted for b }\end{array}$ & $\begin{array}{l}\text { ata, and were } \\
\text { nesian kingf } \\
\text { nost extreme } \\
\text { nographic pa }\end{array}$ & $\begin{array}{l}\text { in accordance wit } \\
\text { moved among soci } \\
\text { ved. }\end{array}$ & $\begin{array}{l}\text { ranked } \\
\text { on the }\end{array}$ \\
\hline
\end{tabular}

Pohnpei study areas (Table 2). Results for $\lambda$ ranged from values indicating severe population declines to values associated with growing populations (Fig. 2). Results further suggested that the overall ranking of elasticities did not differ from the point-estimate model, because adult survival had the highest proportional influence on population dynamics. Simulated demographic parameters were regressed against resulting $\lambda$ estimates to assess the potential importance of each parameter to multiple Pacific Todiramphus kingfisher populations (Table 2; Fig. 3). Adult survival rates had the highest slope $(m=0.94)$, indicating that changes in annual adult survival have greater proportional influence on $\lambda$ than other

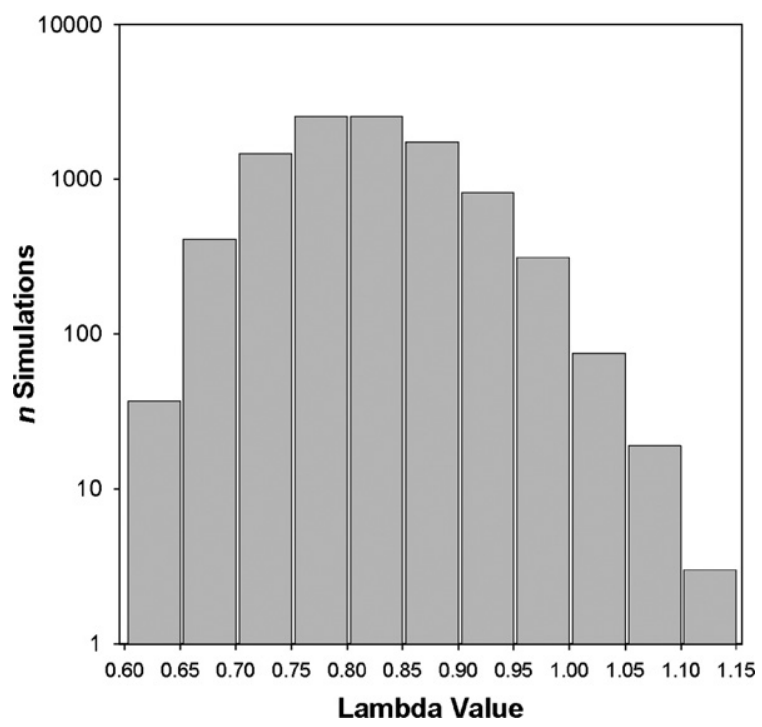

Fig. 2 - Distribution of $\lambda$ values from 10,000 population projection matrix model simulations with varying demographic parameters for cooperatively breeding Micronesian kingfishers. demographic parameters. However, the correlation coefficient for nestling survival was substantially higher than adult survival $\left(r^{2}=0.40\right.$ vs. 0.26$)$, which indicated that the parameter's influence on $\lambda$ was more predictable across the simulated combinations of varied demographic parameters. Regression results further indicated that juvenile survival had substantial influence on population dynamics $(m=0.62)$, whereas the number of nesting attempts, social class transitions and the breeding proportion of the population did not (Fig. 3).

\section{Discussion}

\subsection{Demographic parameter estimates}

We assessed population demographic characteristics in Pohnpei Micronesian kingfishers and used those data to develop a population projection matrix model that could be generalized to other Pacific island Todiramphus kingfishers. To our knowledge no other investigations of demography have been reported for any Pacific Todiramphus kingfisher. When compared to a range of bird species presented by Sæther and Bakke (2000), our estimated survival rate in juvenile Micronesian kingfishers (0.37) was similar to a mean rate in 39 other species (0.40), and survival in after-hatch-year kingfishers (0.58) was lower than the mean reported for 49 adult species (0.72). However, most previous demographic studies focused on species that differ drastically from the year-round resident, territorial, and forest kingfishers of tropical Pacific islands (Oring et al., 1983; Reed and Oring, 1993; Heppell et al., 1994; Anders et al., 1997; Porneluzi and Faaborg, 1999; Daniels and Walters, 2000).

Demographic parameters are often similar among species with like phylogenies, ecologies, and life history patterns. Estimated survival for juvenile and adult Micronesian kingfishers was higher than rates for European kingfishers (Alcedo atthis; 0.22 and 0.28 for juvenile and adult; Bunzel and Drüke, 

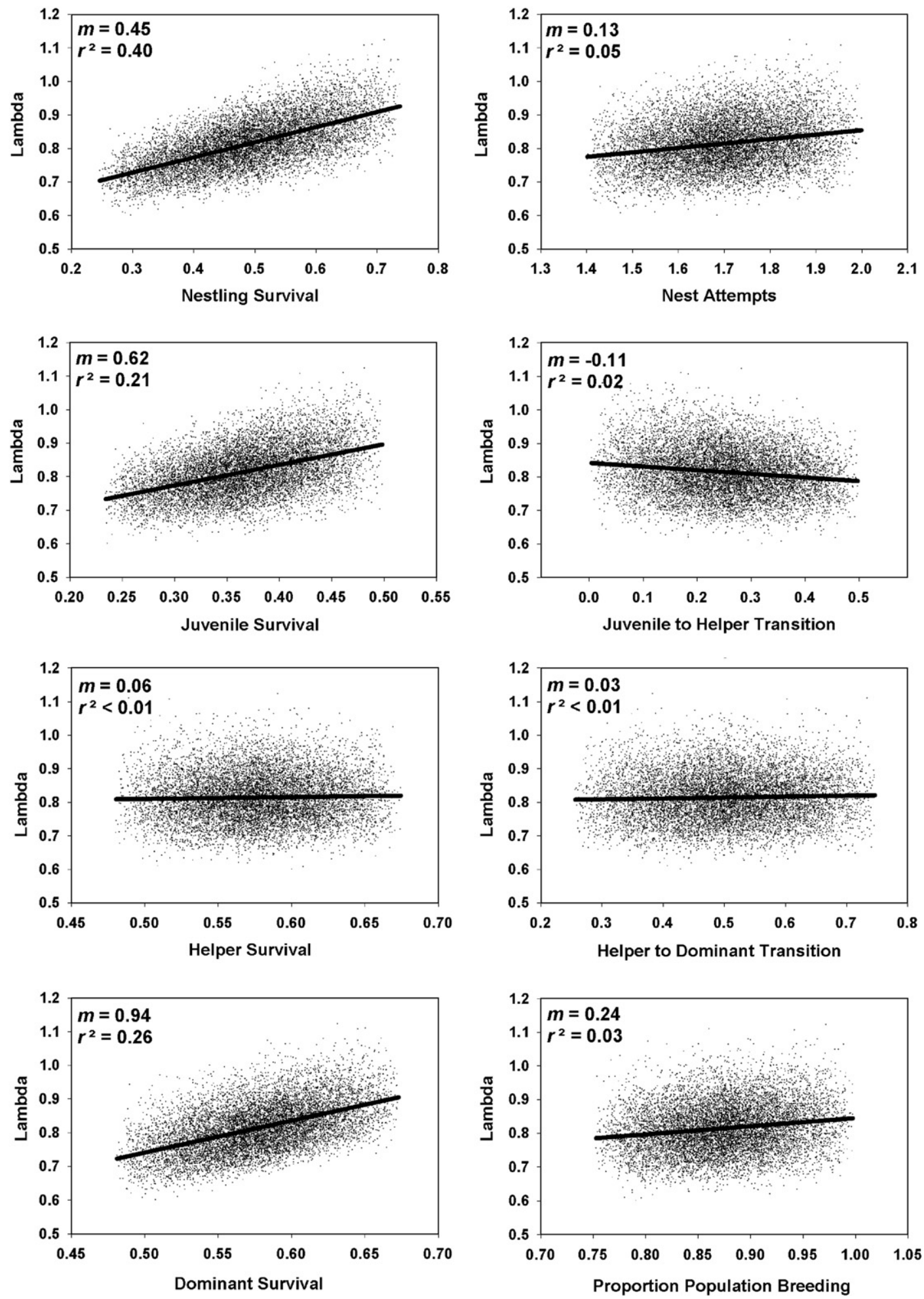

Fig. 3 - Regression of demographic parameters against $\lambda$ values resulting from 10,000 population projection matrix model simulations with varying parameter values. Regression slope values $(m)$ indicate magnitude effects and $r^{2}$ values represent the concordance between demographic parameters and $\lambda$.

1989 in Sæther and Bakke (2000)). Among cooperatively breeding species, survival estimates for Micronesian kingfishers were nearly identical to those for juvenile (0.39) and adult (0.58) Acorn Woodpeckers (Melanerpes formicivorus; Stacey and Taper, 1992; Kendall, 1998 in Sæther and Bakke (2000)).
Juvenile survival in the cooperative Florida Scrub Jay (Aphelocoma coerulescen) was also similar to Micronesian kingfishers (0.35), but woodpecker adult survival was higher (0.83; Woolfenden and Fitzpatrick, 1984 in Sæther and Bakke (2000)). Micronesian kingfisher survival was lower than cooperatively 
breeding Red-cockaded woodpeckers (Picoides borealis), at both the juvenile $(0.50 \mathrm{M}, 0.42 \mathrm{~F})$ and breeder stages $(0.77 \mathrm{M}, 0.71 \mathrm{~F}$; Walters et al., 1988; Letcher et al., 1998).

Some have characterized demography through meta analyses of broad ranges of species (Sæther, 1988; Heppell et al., 2000). For example, population models have classified organisms along a "slow-fast" continuum used to describe life history patterns (Sæther, 1988; Silvertown et al., 1993; Heppell et al., 2000; Sæther and Bakke, 2000). Avian species on the "slow" end of the continuum were long-lived, with small clutches, long maturation periods, and high contributions from adult survival to $\lambda$ (i.e., high elasticity values). Those on the "fast" end exhibited a high contribution of fecundity to $\lambda$, low adult survival, and large clutch sizes (Sæther, 1988; Sæther and Bakke, 2000). Micronesian kingfishers fell toward the slow end of this fast-slow spectrum because they were characterized by higher adult survival contribution to $\lambda$, which were illustrated herein by elevated elasticity estimates. However, the kingfishers were also toward the middle of the spectrum because they matured quickly, as they bred during the first year after hatching, they laid two eggs in each of two clutches, and overall survival estimates were neither extremely high nor low. Accordingly, elasticity estimates from the matrix population models also fell toward the middle of the fast-slow spectrum of elasticities presented by Sæther and Bakke (2000).

\subsection{Population model and analyses}

Estimates for $\lambda$ indicated a declining population of Micronesian kingfishers on Pohnpei. While kingfisher densities remained relatively stable on the study areas throughout the duration of this project (Kesler, personal observation), results from surveys indicated an island-wide decline of as much as 63\% during the last two decades (Buden, 2000; Kesler and Haig, 2007a). Together, these suggested that study areas may have been localized population sinks, and that immigration of individuals from other areas of the island may have been subsidizing study area kingfisher populations.

Elasticity rankings and demographic parameter correlations with $\lambda$ were made to assess the relative influence of demographic parameters on population dynamics across a range of values that might characterize multiple Pacific Todiramphus kingfishers. Parameters with higher elasticity estimates and regression slopes had comparatively greater magnitudinal effects on $\lambda$, whereas the effects of parameters with higher correlation coefficients were more predictable across the range of simulated populations. Both metrics are thought to be of conservation importance (Wisdom and Mills, 1997; Wisdom et al., 2000; Beissinger et al., 2006). Elasticity rankings and regression slopes indicated that changes in adult breeder survival had greater magnitudinal influence on $\lambda$, but correlation coefficient values from simulation analyses indicated that nestling survival was most closely correlated with $\lambda$ across the range of randomly altered parameter estimates. The $\lambda$ estimates presented in Fig. 2 also indicated that there was potential for population growth within the range of parameters used in our simulation. Therefore, results suggested that conservation management for multiple Pacific kingfisher populations has the potential to increase population sizes, and that strategies aimed at increasing both nestling survival and adult survival are most likely to be effective. Furthermore, we believe that these results broadly extend to other Pacific Todiramphus populations because similar results were identified in the point-estimate model and throughout simulation analyses.

The population projection matrix model presented here can be altered to more accurately reflect localized conditions for other congeners. For example, cooperation may not characterize all Pacific Todiramphus species or it may characterize some species but only during times with specific resource conditions. Cooperation is commonly thought to be a response to limited resources (Emlen, 1982), so the occurrence of cooperative behaviors can be influenced by population densities and resource characteristics (Walters et al., 1992; Komdeur, 1994). Thus, conservation practitioners attempting to generalize the projection matrix model to other populations would be best served by adjusting transition parameters toward a pair-breeding model for populations with ample resources, such as reintroduced or translocated populations (i.e. reducing juvenile to helper transition rate).

The observed effect of helper-associated parameters on population dynamics in Micronesian kingfishers was congruent with observations of other cooperative breeders. Heppell et al. (1994) suggested that changes in the proportion of the population serving as helpers in Red-cockaded Woodpeckers (Picoides borealis) had the potential to cause lower $\lambda$ estimates, even if there were no changes in fecundity or survival among dominants. To the contrary, however, previous investigations of behavior suggested that helpers are individuals prevented from breeding and that they would likely transition to a dominant status if opportunities arose (Emlen, 1982; Brown, 1987; Ligon, 1999; Koenig and Dickinson, 2004). Such an interaction would result in a positive influence of helpers on population dynamics, and it could potentially be incorporated into future modeling efforts.

In some cooperatively breeding species, helpers enhance reproductive success (Innes and Johnson, 1994; Langen and Vehrencamp, 1999), whereas they apparently have little or no effect in other species (Bednarz, 1987; Sydeman, 1989; Legge, 2000). Previous investigations of Micronesian kingfishers suggested that there were differences in nestling survival on cooperative and pair-breeding territories (Kesler, 2006), so we used nestling survival rates that spanned the gap for simulations. Coupled with results illustrating that the changes in nestling survival were strongly correlated with $\lambda$, the broad difference between nestling survival on cooperative and pair breeding territories (Kesler, 2006) indicated that there were likely substantial benefits to sociality among Todiramphus kingfishers.

\section{Conclusion}

The goal of this investigation was to provide population evaluation tools for multiple Todiramphus kingfisher populations. These were the first estimates of demographic parameters for any of the 12 endangered Pacific Todiramphus kingfishers and this is one of the first attempts to summarize information into a population demographic model for application to a suite of endangered species. The deterministic model presented here should be viewed as a plastic and foundational 
model that can be enhanced as additional data become available. Enhancements to the generalized model might be implemented within an adaptive management framework, through a flexible Bayesian approach (Frigessi et al., 2005) or through other methods of incorporating data from multiple sources and of varying reliability (Linacre et al., 2004). The generalized population matrix also provides a foundation for localized models directed toward managing single species in specific situations, which might incorporate collateral data, local environmental variation, stochastic environmental events (Lande, 1993), and population-specific demographic parameters (Dugger et al., 2004; LaHaye et al., 2004; Mazerolle et al., 2005). Similarly, the demographic parameters and error estimates presented above might be used singularly or in sets to enhance single species vital-rate based simulation models or population viability analyses.

Population models based on surrogates may provide an appropriate and accurate means of managing translocated and reintroduced populations. Some have suggested that useful population models can be developed after studying a reintroduced population for five years (Armstrong et al., 2002). However, model accuracy and utility might be improved even more rapidly if managers were armed with generalized population models based on surrogates prior to release. Then, post-release monitoring could enhance preexisting models by honing parameter precision and variance estimates, recognizing and correcting biases, and including stochastic and density dependent algorithms. Our model might be employed in exactly such a way during the reintroduction of T. c. cinnamominus to its native habitats on Guam (US Fish and Wildlife Service, 2004), or during the translocation of T. gambieri from Niau to another island in the Tuamotu archipelago, and similar approaches could be used for many other groups (Thibault et al., 2002; Tweed et al., 2003).

Despite their utility, surrogate species data should be used with caution. The problem of bias takes on a new dimension when information from one population is generalized to other populations in regions with different resource and environmental conditions. Although demographic patterns are not always closely correlated with taxonomic distance (Heppell et al., 2000), demography is likely similar among congeners with similar ecologies and that diverged primarily because of isolation by distance. Perhaps one way to mitigate effects of bias is to use a level of caution that is directly related to both taxonomic and ecological distance from the source population.

Future conservation efforts will benefit from research aimed at suites of species. In addition to the 11 genera of birds mentioned above, suites of insular birds in other regions (Grant et al., 2000; Thibault et al., 2002), and anadromous fishes that spawn in similar but disparate watersheds might make good candidates for generalized investigations. Finally, conservation biologists should make a concerted effort to present the potential applications of their data to other populations when publishing.

\section{Acknowledgements}

We are greatly indebted to the following for providing financial support for this work, including USGS Forest and Range- land Ecosystem Science Center, US Fish and Wildlife Service, Conservation Endowment Fund of the American Zoo and Aquarium Association, National Geographic Society, Disney's Animal Kingdom, St. Louis Zoo Field Research for Conservation Fund, Brookfield Zoo, Friends of the National Zoo, the Micronesian Kingfisher Species Survival Fund, Riverbanks Zoo, and the Milwaukee County Zoo. J. Gervais, S. Heppell, and M. Huso provided technical advice integral to model development. We extend special thanks to A. Anders, and the anonymous reviewers who contributed greatly to the quality of the manuscript. We also thank H. Draheim, B. Dugger, E. Elliott-Smith, L. Houck, L. Kesler, N. Johnson, I. Lopes, T. Mullins, P. Sanzenbacher, O. Taft, and J. Walters for their insight and comments. D. Buden, B. Lynch, and B. Raynor provided logistical help on Pohnpei. We also extend thanks to R. Mauricio, the government of the Federated States of Micronesia, the Eischart and Adams families, and other kind Micronesians who allowed access to lands and wildlife. M. Boris, P. Sanzenbacher, J. Santos, and C. Cantero also made contributions as field assistants and cultural guides.

\section{R E F E R E N C E S}

Anders, A.D., Marshall, M.R., 2005. Increasing the accuracy of productivity and survival estimates in assessing landbird population status. Conservation Biology 19, 66-74.

Anders, A.D., Dearborn, D.C., Faaborg, J., Thompson III, F.R., 1997. Juvenile survival in a population of neotropical migrant birds. Conservation Biology 11, 698-707.

Armstrong, D.P., Davidson, R.S., Dimond, W.J., Perrott, J.K., Castro, I., Ewen, J.G., Griffiths, R., Taylor, J., 2002. Population dynamics of reintroduced forest birds on New Zealand islands. Journal of Biogeography 29, 609-621.

Baker, R.H., 1951. The Avifauna of Micronesia, its Origin, Evolution, and Distribution. University of Kansas Museum of Natural History. Lawrence.

Bar-David, S., Saltz, D., Dayan, T., Perelberg, A., Dolev, A., 2005. Demographic models and reality in reintroductions: Persian fallow deer in Israel. Conservation Biology 19, 131-138.

Bednarz, J.C., 1987. Pair and group reproductive success, polyandry, and cooperative breeding in Harris' Hawks. Auk 104, 393-404.

Beissinger, S.R., McCullough, D.R., 2002. Population Viability Analysis. University of Chicago Press, Chicago.

Beissinger, S.R., Walters, J.R., Catanzaro, D.G., Smith, K.G., Dunning Jr., J.B., Haig, S.M., Noon, B.R., Smith, B.M., 2006. Modeling approaches in avian conservation and the role of field biologists. Ornithological Monographs 123 (S), 1-56.

Brown, J.L., 1987. Helping and Communal Breeding in Birds: Ecology and Evolution. Princeton University Press, Princeton.

Buden, D.W., 2000. A comparison of 1983 and 1994 bird surveys of Pohnpei, Federated States of Micronesia. Wilson Bulletin 112, 403-410.

Bunzel, M., Drüke, J., 1989. Kingfisher. In: Newton, I. (Ed.), Lifetime Reproduction in Birds. Academic Press, London, pp. 107-116.

Burnham, K.P., Anderson, D.R., 2002. Model Selection and Multimodel Inference: a Practical Information-theoretic Approach. Springer, New York.

Casswell, H., 2000. Prospective and retrospective perturbation analyses: their roles in conservation biology. Ecology 81, 619627. 
Caswell, H., 2001. Matrix Population Models: Construction, Analysis, and Interpretation. Sinauer Associates, Sunderland.

Caughley, G., Gunn, A., 1996. Conservation Biology in Theory and Practice. Blackwell Science, Massachusetts.

Daniels, S.J., Walters, J.R., 2000. Inbreeding depression and its effects on natal dispersal in Red-Cockaded Woodpeckers. Condor 102, 482-491.

Doak, D.F., Gross, K., Morris, W.F., 2005. Understanding and predicting the effects of sparse data on demographic analyses. Ecology 86, 1154-1163.

Dugger, K.M., Faaborg, J., Arendt, W.J., Hobson, K.A., 2004. Understanding survival and abundance of overwintering warblers: Does rainfall matter? Condor 106, 744-760.

Emlen, S.T., 1982. The evolution of helping. I. An ecological constraints model. American Naturalist 119, 29-39.

Engbring, J., Ramsey, F.L., Wildman, V., 1990. Micronesian Forest Bird Surveys, the Federated States: Pohnpei, Kosrae, Chuuk, and Yap. Report to the US Fish and Wildlife Service. US Fish and Wildlife Service, Honolulu.

Frigessi, A., Holden, M., Marshall, C., Viljugrein, H., Stenseth, N.C., Holden, L., Ageyev, V., Klassovskiy, N.L., 2005. Bayesian population dynamics of interacting species: great gerbils and fleas in Kazakhstan. Biometrics Journal 61, 230-238.

Fox's Team. 2005. Matrix and Linear Algebra Package for Excel. Version 1.9. Rome. Available from: <http://digilander.libero.it/ foxes/index.htm>.

Fry, C.H., Fry, K., 1992. Kingfishers, Bee-eaters, and Rollers. Princeton University Press, Princeton.

Grant, P.R., Curry, R.L., Grant, B.R., 2000. A remnant population of the Floreana mockingbird on Champion island, Galapagos. Biological Conservation 92, 285-290.

Haig, S.M., Ballou, J.D., 1995. Genetic diversity in two avian species formerly endemic to Guam. Auk 112, 445-455.

Haig, S.M., Ballou, J.D., Casna, N.J., 1995. Genetic identification of kin in Micronesian Kingfishers. Journal of Heredity 86, 423-431.

Heppell, S.S., Walters, J.R., Crowder, L.B., 1994. Evaluating management alternatives for red-cockaded woodpeckers: a modeling approach. Journal of Wildlife Management 58, 479-487.

Heppell, S.H., Caswell, H., Crowder, L.R., 2000. Life histories and elasticity patterns: perturbation analysis for species with minimal demographic data. Ecology 81, 654-665.

Innes, K.E., Johnson, R.E., 1994. Cooperative breeding in the whitethroated magpie-jay. how do auxiliaries influence nesting success? Animal Behaviour 51, 519-533.

International Union for Conservation and Natural Resources., 2004. IUCN Red List of Threatened Species. Gland, Switzerland. http://www.iucnredlist.org (downloaded January 2005).

Johnson, T.H., Stattersfield, A.J., 1990. A global review of island endemic birds. Ibis 132, 167-180.

Kaplan, E.L., Meier, P., 1958. Nonparametric estimation from incomplete observations. Journal of the American Statistics Association. 53, 457-481.

Kendall, B.E., 1998. Estimating the magnitude of environmental stochasticity in survivorship data. Ecological Applications 8, 184-193.

Kesler, D.C., 2002. Nest site selection in cooperatively breeding Pohnpei Micronesian Kingfishers (Halcyon cinnamomina reichenbachii): does nest-site abundance limit reproductive opportunities? MS thesis. Oregon State University.

Kesler, D.C., 2006. Population demography, resource use, and movement in cooperatively breeding Micronesian Kingfishers. Dissertation, Oregon State University.

Kesler, D.C., Haig, S.M., 2004. Thermal characteristics of wild and captive Micronesian kingfisher nesting habitats. Zoo Biology 23, 301-308.
Kesler, D.C., Haig, S.M., 2005a. Selection of arboreal termitaria for nesting by cooperatively breeding Pohnpei Micronesian Kingfishers. Ibis 147, 188-196.

Kesler, D.C., Haig, S.M., 2005b. Microhabitat and nest site selection in Micronesian Kingfishers. Pacific Science 59, 499-508.

Kesler, D.C., Haig, S.M., 2007a. Multi-scale habitat use and selection in cooperatively breeding Micronesian Kingfishers. Journal of Wildlife Management 72, in press.

Kesler, D.C., Haig, S.M., 2007b. Territoriality, prospecting, and dispersal in cooperatively breeding Micronesian Kingfishers. Auk 124, in press.

Kesler, D.C., Lopes, I.F., Haig, S.M., 2006. Sex determination in the Pohnpei Micronesian Kingfisher using morphological and molecular genetic techniques. Journal of Field Ornithology 77 229-236.

Koenig, W.D., Dickinson, J.L., 2004. Ecology and Evolution of Cooperative Breeding in Birds. Cambridge University Press, New York.

Komdeur, J., 1994. Experimental evidence for helping and hindering by previous offspring in the cooperative-breeding Seychelles Warbler Acrocephalus sechellensis. Behavioral Ecology and Sociobiology 34, 175-186.

LaHaye, W.S., Zimmerman, G.S., Gutierrezz, R.J., 2004. Temporal variation in the vital rates of an insular population of Spotted Owls (Strix occidentalis occidentalis). Auk 121, 1056-1069.

Lande, R., 1993. Risks of population extinction from demographic and environmental stochasticity and random catastrophes. American Naturalist 142, 911-927.

Langen, T.A., Vehrencamp, S.L., 1999. How White-Throated Magpie-Jay helpers contribute during breeding. Auk 116, 131-140.

Lebreton, J.D., Burnham, K.P., Clobert, J., Anderson, D.R., 1992. Modeling survival and testing biological hypotheses using marked animals: a unified approach with case-studies. Ecological Monographs 62, 67-118.

Legge, S., 2000. Helper contributions in the cooperatively breeding laughing kookaburra: feeding young is no laughing matter. Animal Behaviour 59, 1009-1018.

Letcher, B.H., Priddy, J.A., Walters, J.R., Crowder, L.B., 1998. An individual-based, spatially-explicit simulation model of the population dynamics of the endangered red-cockaded woodpecker, Picoides borealis. Biological Conservation 86, $1-14$.

Ligon, J.D., 1999. The Evolution of Avian Breeding Systems. Oxford University Press, Oxford.

Linacre, N.A., Stewart-Oaten, A., Burgman, M.A., Ades, P.K., 2004 Incorporating collateral data in conservation biology. Conservation Biology 18, 768-774.

Marshall, S.D., 1989. Nest sites of the Micronesian Kingfisher on Guam. Wilson Bulletin 101, 472-477.

Mayr, E., Diamond, J., 2001. The birds of Northern Melanesia. Oxford University Press, New York.

Mazerolle, D.F., Dufour, K.W., Hobson, K.A., den Haan, H.E., 2005. Effects of large-scale climatic fluctuations on survival and production of young in a Neotropical migrant songbird, the Yellow Warbler Dendroica petechia. Journal of Avian Biology 36, 155-163.

Microsoft Corporation. 2000. Microsoft Excel 2000. Redmond.

Morris, W.F., Doak, D.F., 2002. Quantitative Conservation Biology: Theory and Practice of Population Viability Analysis. Sinauer Associates, Sunderland.

Mueller-Dombois, D., Fosberg, F.R., 1998. Vegetation of the Tropical Pacific Islands. Springer, New York.

Oring, L.W., Lank, D.B., Maxon, S.J., 1983. Population studies of polyandrous Spotted Sandpiper. Auk 100, 272-285.

Pollock, K.H., Nichols, J.D., Brownie, C., Hines, J.E., 1990. Statistical inference for capture-recapture experiments. Wildlife Monographs 107, 1-97. 
Porneluzi, P.A., Faaborg, J., 1999. Season-long fecundity, survival, and viability of ovenbirds in fragmented and unfragmented landscapes. Conservation Biology 13, 1151-1161.

Pratt, H.D., Bruner, P.L., Berrett, D.G., 1987. A Field Guide to the Birds of Hawaii and the Tropical Pacific. Princeton University Press, Princeton.

Rappole, J.H., Tipton, A.R., 1991. New harness design for attachment of radio transmitters to small passerines. Journal of Field Ornithology 62, 335-337.

Reed, J.M., Oring, L.W., 1993. Philopatry, site fidelity, dispersal and survival of Spotted Sandpipers. Auk 110, 541-551.

Ruggiero, L.F., Hayward, G.D., Squires, J.R., 1994. Viability analysis in biological evaluations: concepts of population viability analysis, biological population, and ecological scale. Conservation Biology 8, 364.

Sæther, B.E., 1988. Pattern of covariation between life history traits of European birds. Nature 331, 616-627.

Sæther, B.E., Bakke, ̌̌., 2000. Avian life history variation and contribution of demographic traits to the population growth rate. Ecology 81, 642-653.

SAS Institute. 1999. The SAS System for Windows version 8e. Cary, NC.

Silvertown, J., Franco, M., Pisanty, I., Mendoza, A., 1993. Comparative plant demography - relative importance of life cycle components to the finite rate of increase in woody and herbaceous perennials. Journal of Ecology 81, 465-476.

Stacey, P.W., Taper, M., 1992. Environmental variation and the persistence of small populations. Ecological Applications 2, 18-29.

Sydeman, W.J., 1989. Effects of helpers on nestling care and breeder survival in Pygmy Nuthatches. Condor 91, 147-155.

Thibault, J.-C., Martin, J.-L., Penloup, A., Meyer, J.-Y., 2002. Understanding the decline and extinction of monarchs (Aves) in Polynesian Islands. Biological Conservation 108, 161-174.
Tweed, E.J., Foster, J.T., Woodworth, B.L., Oesterle, P., Kuehler, C., Lieberman, A.A., Powers, A.T., Whitaker, K., Monahan, W.B., Kellerman, J., Telfer, T., 2003. Survival, dispersal, and home-range establishment of reintroduced captivebred puaiohi, Myadestes palmeri. Biological Conservation 111, 1-9.

US Fish and Wildlife Service, 1984. Endangered and threatened wildlife and plants: determination of endangered status for seven birds and two bats on Guam and the Northern Mariana Islands. Federal Register 50 CFR Part 17 49(167), 33881-33885.

US Fish and Wildlife Service, 2004. Draft Revised Recovery Plan for the Sihek or Guam Micronesian Kingfisher (Halcyon cinnamomina cinnamomina). US Fish and Wildlife Service, Portland.

Walters, J.R., Doerr, P.D., Carter III, J.H., 1988. The cooperative breeding system of the Red-cockaded woodpecker. Ethology 78, 275-305.

Walters, J.R., Copeyon, C.K., Carter III, J.H., 1992. Test of the ecological basis of cooperative breeding in Red-cockaded Woodpeckers. Auk 109, 90-97.

White, G.C., 2005. Program Mark V5.0. Fort Collins, CO. Available from: <http://www.cnr.colostate.edu/ gwhite/mark/ mark.htm\#Introduction> (downloaded February 2005).

Williams, B.K., Nichols, J.D., Conroy, M.J., 2001. Analysis and Management of Animal Populations. Academic Press, New York.

Wisdom, M.J., Mills, L.S., 1997. Sensitivity analysis to guide population recovery: prairie-chickens as an example. Journal of Wildlife Management 61, 302-312.

Wisdom, M.J., Mills, L.S., Doak, D.F., 2000. Life-stage simulation analysis: estimating vital rate effects on population growth for conservation. Ecology 81, 628-641.

Woolfenden, G.E., Fitzpatrick, J.W., 1984. The Florida Scrub Jay. Princeton University Press, Princeton. 